\title{
TRIPLE TEST CROSS ANALYSIS IN TWO WHEAT CROSSES
}

\author{
SULTAN SINGH \\ Department of Agricultural Botany, J. V. College, Baraut \\ and
}

R. B. SINGH

Department of Genetics and Plant Breeding, B.H.U., Varanasi

Received 27.i.76

\begin{abstract}
SUMmary
Modified triple test cross analysis described by Jinks and Perkins (1970) has been applied to the study of additive, dominance and epistatic components of genetic variance for five metric traits, namely final plant height, ear length, number of spikelets per spike, number of grains per spike and grain yield per plant, in two wheat crosses (Kalyan Sona $\times$ Norteno 67 and Norteno $67 \times$ WL 212). The results of the analysis reveal that the epistatic component is an important element in both the crosses for all the five characters.
\end{abstract}

\section{Introduction}

Most genetic models, particularly those for second-degree statistics, which have been developed to estimate the components of continuous variation, have as one of their simplifying assumptions the absence of epistasis. This assumption may be true for some characters in some populations but not for others. Very few analyses, however, provide a valid test for this. A good genetic model, in fact, is that which enables the breeder to have precise and unbiased estimates of all the components of genetic variance. A design which is a simple extension of the design III of Comstock and Robinson (1952) has been proposed by Kearsey and Jinks (1968). This design, known as " triple test cross", provides not only a precise test for epistasis but also gives unbiased estimates of additive $(D)$ and dominance $(H)$ components if epistasis is absent. Further, this approach is independent of both the gene frequencies and the mating system of the population to be investigated.

Jinks and Perkins (1970) have suggested a modification in the triple test cross analysis and applied it to $\mathrm{F}_{2}$ and backcross populations of Nicotiana rustica. In the modified analysis, all comparisons among the three kinds of progeny means, namely $\bar{L}_{1 i}\left(\mathrm{~F}_{2} \times \mathrm{P}_{1}\right), \bar{L}_{2 i}\left(\mathrm{~F}_{2} \times \mathrm{P}_{2}\right)$ and $\bar{L}_{3 i}\left(\mathrm{~F}_{2} \times \mathrm{F}_{1}\right)$, are orthogonal to one another and, in the absence of epistasis, the $L_{3}$ families are used to provide additional information about the additive component.

\section{Materials and methods \\ (i) Experimental design}

Twenty plants were randomly chosen from each of the two $F_{2}$ 's, namely Kalyan Sona $\times$ Norteno 67 and Noretno $67 \times W L 212$. In each $F_{2}$ the 20 plants were backcrossed, as male parent, to the same three testers, $\mathrm{P}_{1}, \mathrm{P}_{2}$ and $F_{1}\left(P_{1} \times P_{2}\right)$, where $P_{1}$ and $P_{2}$ are the varieties Kalyan Sona and 
Norteno 67 for the $\mathrm{F}_{2}$ of the cross between them and the varieties Norteno 67 and WL 212 for the $\mathrm{F}_{2}$ of the cross between these two varieties. Sixty families (from each original cross), thus obtained, were raised in completely randomised blocks with three replications. From each family in each replication, five plants were randomly tagged. Each of these tagged plants was scored for five characters, namely, final plant height, ear length, number of spikelets per spike, number of grains per spike and grain yield per plant. Data for analysis were, therefore, based on 180 values, each being the mean of five plants and the corresponding variances of these sets of five plants.

Jinks and Perkin's (1970) analysis was applied to detect epistasis and to test and estimate additive and dominance components of genetic variation.

\section{(ii) Test for epistasis}

For the test of epistasis, twenty values of $L_{1 i}+L_{2 i}-2 L_{3 i}$, for $i=1$ to 20 were obtained for each of the three replicates. After summing over the replicates, the sum of twenty squared deviations of $L_{1 i}+\bar{L}_{2 i}-L_{3 i}$ from zero for 20 degrees of freedom, that is, sum of squares due to epistasis, was obtained. Sum of squares due to replicate error, that is, the error for testing the significance of epistasis, was obtained for 40 degrees of freedom. A further estimate of the error variance was obtained by the mean variance within the $L_{1}, L_{2}$ and $L_{3}$ types of families for 720 degrees of freedom.

This analysis was, however, pursued further. The epistasis sum of squares for 20 degrees of freedom could be partitioned into an item for 1 degree of freedom, testing for $i$ type epistasis (homozygote $\times$ homozygote interactions) and an item for 19 degrees of freedom testing for $j$ and $l$ types of epistasis (homozygote $\times$ heterozygote and heterozygote $\times$ heterozygote interactions, respectively). Similarly, the sum of squares due to replicate error for 40 degrees of freedom could be subdivided into two items, namely replicates and epistasis $\times$ replicates, respectively, for 2 and 38 degrees of freedom.

\section{(iii) Test and estimation of additive and dominance components}

Additive and dominance components were estimated, assuming no epistasis. The 20 sums of means of the families yielded a variance of sums for 19 degrees of freedom. Similarly, the variance of differences was obtained further for 19 degrees of freedom. Variances of sums $\times$ replicates and differences $\times$ replicates were obtained each for 38 degrees of freedom.

\section{Results \\ (i) Epistasis}

Significant epistasis was recorded for all the five characters in both the triple test crosses (table 1). Further partitioning of the epistasis item, however, revealed that overall epistasis ( $i$ type) was not significant for the character spikelets per spike in the first triple test cross $(K$. Sona $\times$ Norteno 67) and for final plant height, ear length and spikelets per spike in the second (Norteno $67 \times$ WL 212). Whereas the item replicate error was significant for all the characters in both triple test crosses except for yield 
per plant in first cross and ear length in the second cross, the item replicates was insignificant for all the traits in both the sets except for final plant height and spikelets per spike in the second triple test cross. Epistasis $\times$ replicate interaction was significant for all the characters in both the triple test crosses except for yield per plant in the first cross.

TABLE 1

Analysis of variance to test for epistasis in two triple test crosses, 1 (K. Sona $\times$ Norteno 67) and 2 (Norteno $67 \times$ WL212) for five characters in wheat

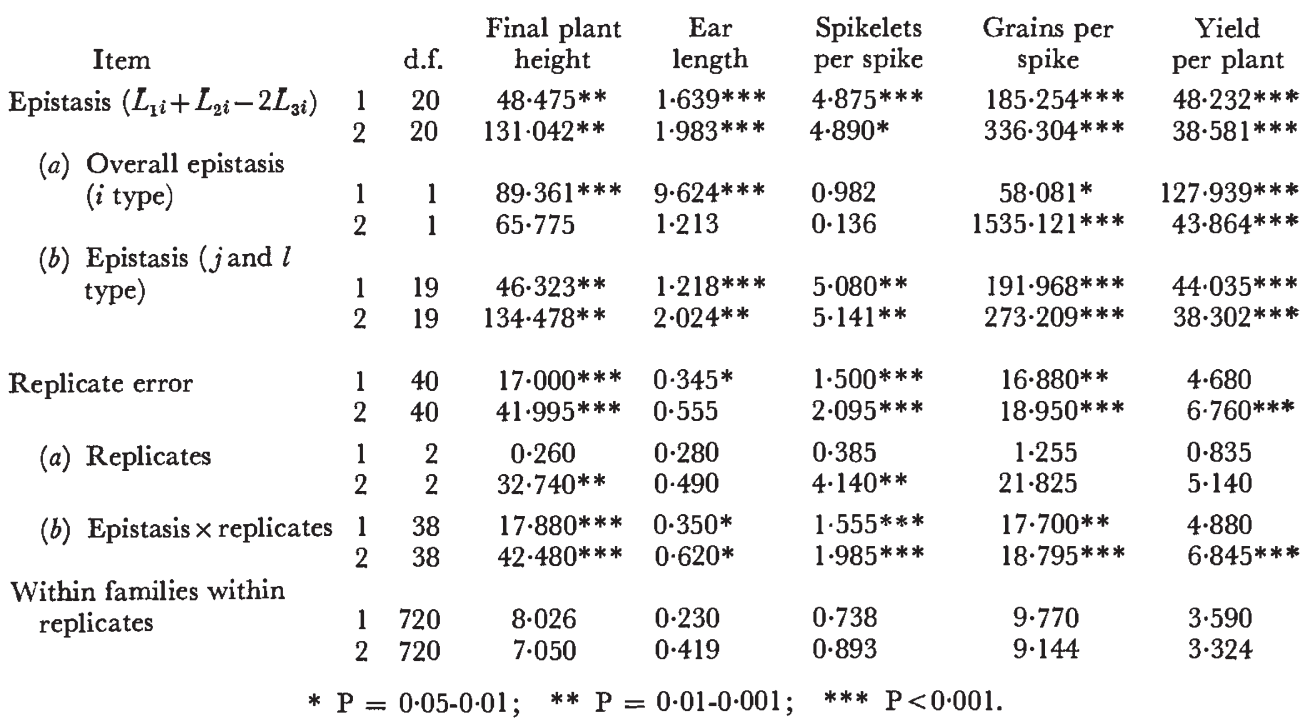

(ii) Additive and dominance components

In the absence of epistasis analysis of variance for sums and differences provides direct tests of the significance of the additive (significance of sums) and dominance component (significance of differences). Both items, the sums and differences, were significant in both the triple test crosses for all the characters studied (table 2). Accordingly, the components $D$ and $H$ were significant for all the traits in both the sets (table 3). As regards the relative magnitudes of additive and dominance components, estimates of $D$ were higher than those of $H$ for all the traits except final plant height in the first triple test cross. The second triple test cross, however, presented a quite different picture. In this, higher estimates of $D$ (as compared to those of $H$ ) were recorded only for one character, namely ear length. The remaining four characters gave relatively higher estimates of $H$. But since both the crosses gave evidence of significant epistasis for all the five characters, these estimates of $D$ and $H$ were biased by epistasis to an unknown extent. Only one character final plant height gave higher estimates of $H$ (as compared to those of $D$ ) with a large epistasis in both the crosses, indicating that the additive component of genetic variation is relatively less important for this character. The item sums $\times$ replicates, was significant in both the triple test crosses for all the five traits. Differences $\times$ replicates interaction 
was also significant for all the characters except for grains per spike in the first triple test cross and ear length in the second triple test cross.

TABle 2

Analysis of variance to detect additive and dominance components in two triple test crosses (TTC) for five characters in wheat

\begin{tabular}{|c|c|c|c|c|c|}
\hline Item & d.f. & $\begin{array}{c}\text { Final plant } \\
\text { height }\end{array}$ & $\begin{array}{c}\text { Ear } \\
\text { length }\end{array}$ & $\begin{array}{l}\text { Spikelets } \\
\text { per spike }\end{array}$ & $\begin{array}{l}\text { Grains per } \\
\text { spike }\end{array}$ \\
\hline
\end{tabular}

TTC 1 (K. Sona $\times$ Norteno 67):

(a) Analysis of sums

$$
\left(L_{1 i}+L_{2 i}+L_{3 i}\right)
$$

Replicates

Sums (Additive component)

Sums $\times$ replicates

Within families 19

38
38
720

(b) Analysis of differences $\left(L_{1 i}-L_{2 i}\right)$

Differences (Dominance component)

Differences $\times$ replicates

Within families

19
38
480

$142 \cdot 674 * * *$
$19 \cdot 000 * * *$
$7 \cdot 203$

1

$0.475 * *$ $0 \cdot 238$

$2 \cdot 895 *$
$1 \cdot 510^{* * *}$
$0 \cdot 698$

$38 \cdot 605 * * *$

$10 \cdot 224 * * *$ 3.529

TTC 2 (Norteno $67 \times$ WL 212):

(a) Analysis of sums

$$
\left(L_{1 i}+L_{2 i}+L_{3 i}\right)
$$

Replicates

Sums (Additive component)

Sums $\times$ replicates

Within families

(b) Analysis of differences $\left(L_{1 i}-L_{2 i}\right)$

Differences (Dominance component)

Differences $\times$ replicates

Within families

$\begin{array}{rcl}19 & 136 \cdot 483^{* *} & 1 \cdot 460 * * \\ 38 & 41 \cdot 745 * * * & 0 \cdot 375 \\ 480 & 6.877 & 0.670\end{array}$

$\begin{array}{rcl}2 & 8 \cdot 450 & 2 \cdot 475 * * \\ 19 & 118 \cdot 416 * * & 6 \cdot 109 * * * \\ 38 & 38 \cdot 945 * * * & 0 \cdot 600 * \\ 720 & 7 \cdot 050 & 0 \cdot 419\end{array}$

$0 \cdot 525$

$8 \cdot 448 * * *$

$1.995 * * *$

$0 \cdot 898$
$1 \cdot 200$

$0 \cdot 260$

$360 \cdot 575 * * *$

$58 \cdot 388 * * *$

$9 \cdot 915 * * *$

$3 \cdot 324$

$$
* \mathrm{P}=0.05-0.01 ; \quad * * \mathrm{P}=0 \cdot 01-0.001 ; * * * \mathrm{P}<0.001 \text {. }
$$

TABLE 3

Estimates of additive (D) and dominance (H) components in two triple test crosses for five characters in wheat

\section{Item}

TTC 1 (K. Sona $\times$ Norteno 67):

D

TTC 2 (Norteno $67 \times$ WL 212):

$D$

$\begin{array}{rllrr}70 \cdot 641 * * & 4 \cdot 897 * * * & 5 \cdot 736 * * * & 307 \cdot 431 * * * & 43.087 * * * \\ 126 \cdot 317 * * & 1.447 * * & 5 \cdot 911 * * * & 402.587 * * * & 121 \cdot 103 * * * \\ * \mathrm{P}=0.05-0.01 ; * * \mathrm{P}=0.01-0.001 ; & * * * \mathrm{P}<0 \cdot 001 .\end{array}$

\section{Discussion}

The results of the present study reveal that all the three kinds of variances, namely additive, dominance and epistatic, are significant for all the char- 
acters in both the triple test crosses. Absence of significant $i$ type epistasis for the character spikelets per spike in the first and for final plant height, ear length and spikelets per spike in the second triple test cross, however, indicates that overall epistasis is a relatively minor component of epistasis for these characters. Because of the bias caused by epistasis no precise conclusion can be drawn about the relative importance of the three components of genetic variation on the basis of the biased estimates of $D$ and $H$. However, high estimates of $H$ combined with the large mean square for epistasis for final plant height in both the crosses indicate that probably epistatic and dominance components are relatively more important for the control of this character. The two triple test crosses gave contrasting results with regard to the relative magnitudes of $D$ and $H$, except for the characters final plant height and ear length.

These results indicate that an epistatic component plays an important role in governing all the five characters studied in these wheat crosses. Therefore, this component cannot be ignored when one is formulating breeding plans to improve wheat populations for economic traits. If the presence of epistasis is ignored in wheat populations (which has been a general trend in the past), one would not only lose information about epistasis but also the estimates of additive and dominance components would be biased as they are in the present crosses and, therefore, could be misleading. Further, the detection and estimation of epistasis would enable the breeder to determine the genetic cause of heterosis with greater reliance.

\section{REFERENCES}

COMSTOCK, R. E., AND ROBINSON, H. F. 1952. Estimation of average dominance of genes. Heterosis, Ch. 30. Iowa State College Press.

JINKS, J. L., AND PERKINS, J. M. 1970. A general method for the detection of additive, dominance and epistatic components of variation. III. $F_{2}$ and Backcross Populations. Heredity, 25, 419-429.

KEARSEY, M. J., AND JINKS, J. L. 1968. A general method of detecting additive, dominance and epistatic variation for metrical traits. I. Theory. Heredity, 23, 403-409. 